\title{
A Comparative Study of the Status of Control on the Epidemic of Heart Coronary Artery Diseases in Selected Countries and Iran
}

\author{
Vida Sadeghzadeh ${ }^{1}$, Katayoun Jahangiri ${ }^{2, *}$, Mahmood Mahmoodi \\ Majdabadi Farahani ${ }^{3}$, Mahmonir Mohammadi ${ }^{4}$
}

${ }^{1}$ PhD Candidate of Health Services Management, Department of Health Services

Administration, Science and Research Branch, Islamic Azad University, Tehran, Iran

${ }^{2}$ MD, MPH. PhD, Associate Professor, Health in Disasters and Emergencies Department,

School of Health, Safety and Environment, Shahid Beheshti University of Medical Sciences,

Tehran, Iran

${ }^{3} \mathrm{PhD}$, Professor, Department of Health Services Administration, Science and Research

Branch, Islamic Azad University, Tehran, Iran

${ }^{4} \mathrm{MD}$, Instructor; Department of Cardiology, Medical Sciences Branch, Islamic Azad

University, Tehran, Iran

* Corresponding author: Katayoun Jahangiri, MD, MPH. PhD, Associate Professor, Health in Disasters and Emergencies Department, School of Health, Safety and Environment, Shahid Beheshti University of Medical Sciences, Tehran, Iran. E-mail: k.jahangiri@ sbmu.ac.ir

Received: 23 Sep 2017

Accepted: 08 Jan 2018

\begin{abstract}
Introduction: Coronary heart disease risk factors assessment and control is critical for preventing cardiovascular attacks and improving the health of people. The aim of the present study was to compare the status of control of the epidemic of heart coronary artery diseases in selected countries and Iran.

Methods: This comparative study was carried out in 11 countries (with define criteria). Databases, such as Medline, PubMed, Rozent, Elsevier, and Google Scholar were used with keywords of "Non communicable diseases", "coronary artery disease", "cardiovascular disease", and "epidemic control". Ninety printed and electronic articles were obtained. Data was collected using "Check List of Control on the Epidemic of Heart Coronary Artery Diseases" in five dimensions with 35 items. The content validity index of the check list was evaluated and confirmed with 17 experts and Cronbach's alpha with 12 experts.

Results: The findings of this study showed similarities, for instance all countries had common risk factors for coronary artery disease. Most countries, had responsive systems for controlling and preventing coronary artery diseases in their structure. The differences included major issues, such as "total expenditure on health as a percentage of gross domestic product", "general government expenditure on health as a percentage of total expenditure on health", "private expenditure on health as a percentage of total expenditure on health", "general government expenditure on health as a percentage of total government expenditure", and "social security expenditure on health as a percentage of general government expenditure on health". Also, "out-of-pocket expenditure as a percentage of private expenditure on health" was very different in Iran compared with the selected countries.

Conclusions: The comparison of responsive systems, health financing, and risk factors for coronary artery disease in Iran and selected countries had several differences and similarities. It is suggested to create a policy framework for regulation and public education for the prevention and control of coronary heart disease.
\end{abstract}

Keywords: Coronary Artery Disease, Disease Control, Comparative Study 


\section{وضعيت كنترل همه كيرى بيمارىهاى عروق كرونر قلب در ايران و كشورهاى منتخب: يك مطالعه تطبيقى}

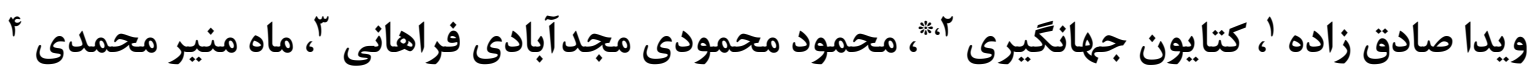

'دانشجوى دكترى مديريت خدمات بهداشتى و درمانى، كروه مديريت خدمات بهداشتى و درمانى، واحد علوم و تحقيقات، دانشكاه آزاد اسلامى، تهران، ايران

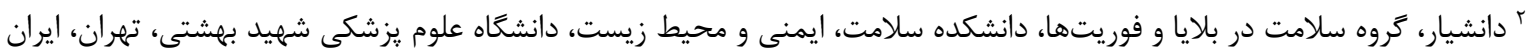

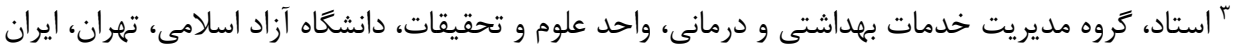

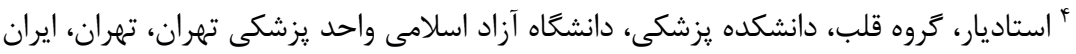

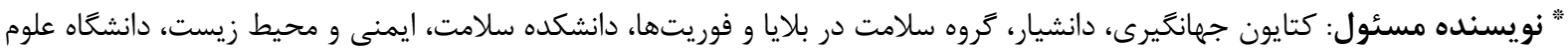
k.jahangiri@sbmu.ac.ir : يزشكى شهيد بهشتى، تهران،

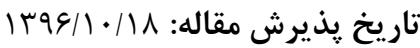

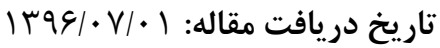

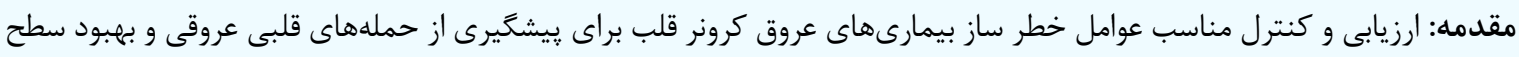

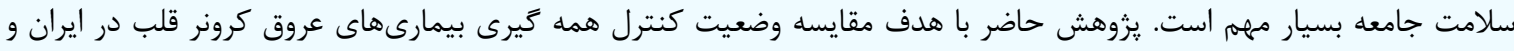
كشورهاى منتخب انجام كرفت.

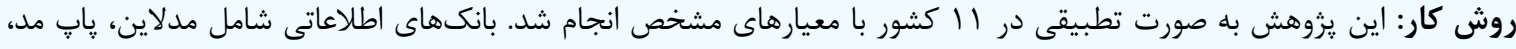

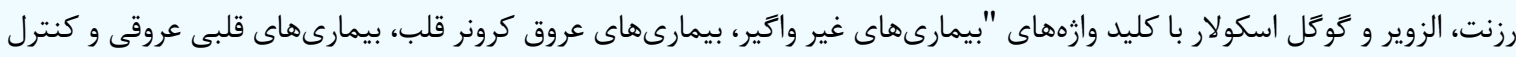

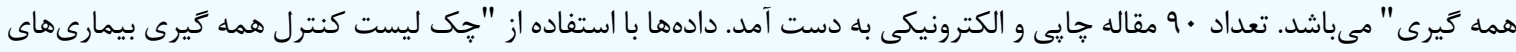

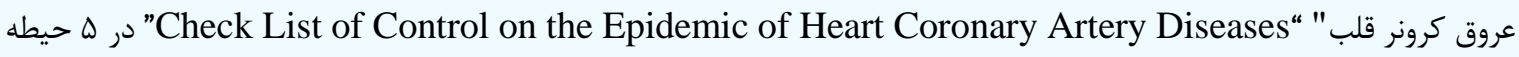

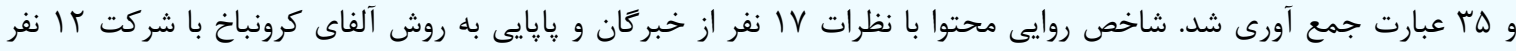

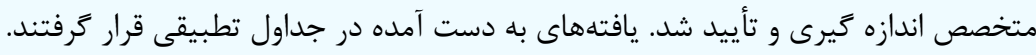

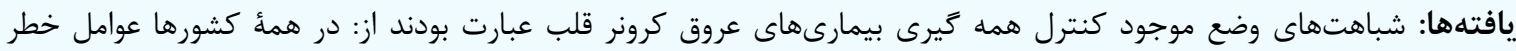

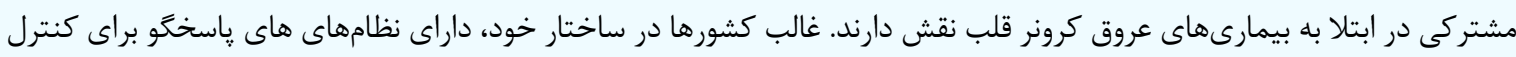

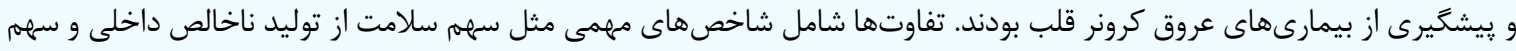

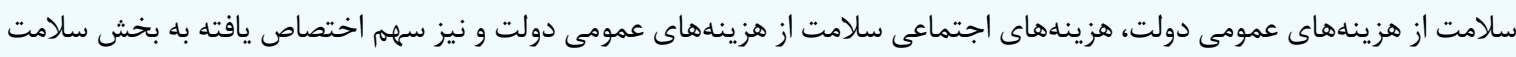

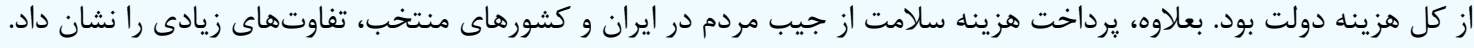

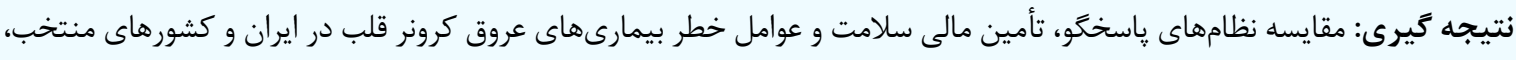

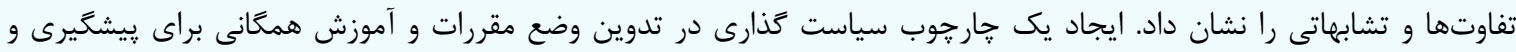

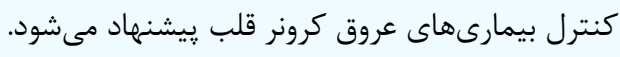

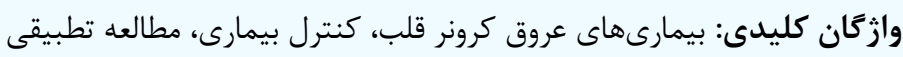

هستند، علت عمده فقر و نكرانى در خانوادهها هستند. سلامت

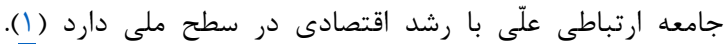

سلامت جامعه ارتباط مستقيم با رشد اقتصادى هر كشور دارد و

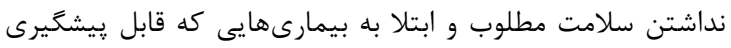


كرونرى قلب در كشورهاى با درآمد كم تا متوسط رخ مى مدهد. از

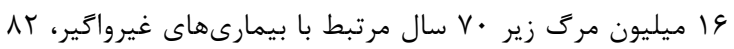

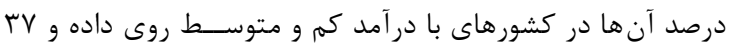

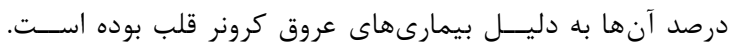

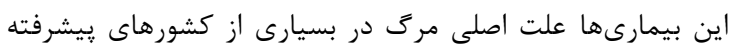

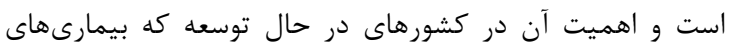

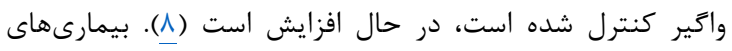

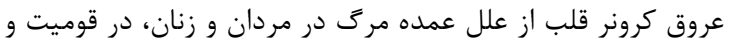

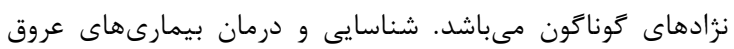

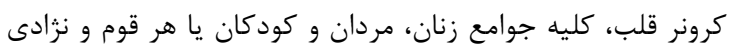

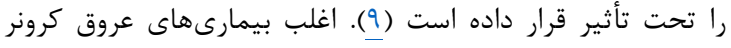

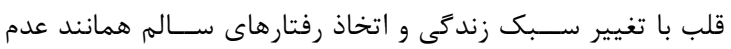

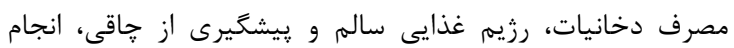

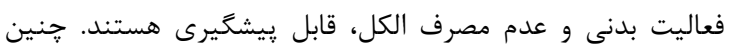

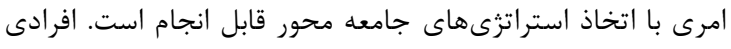

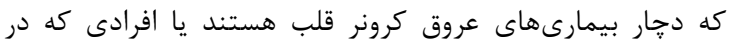

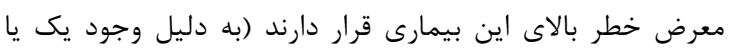

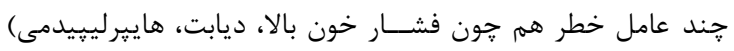

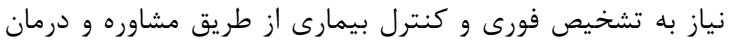
دارويى دارند (· ()). بيمارىهاى عروق كرونر قلب هزينه هنَّفتى را بر نظامهاى

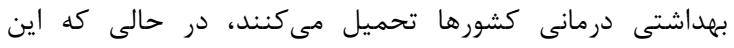

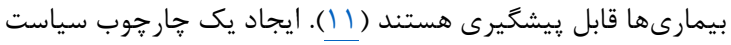

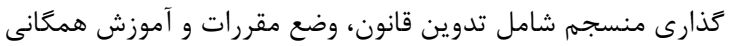

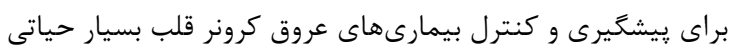

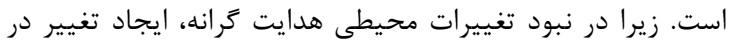

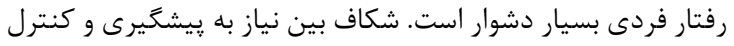

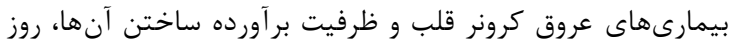

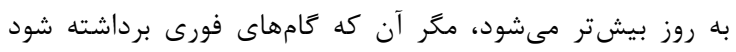

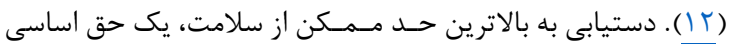

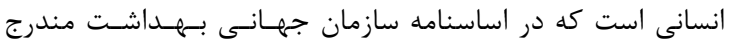

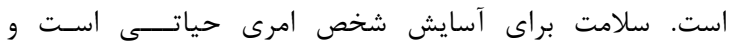

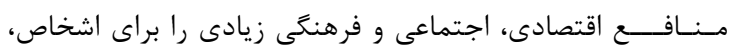

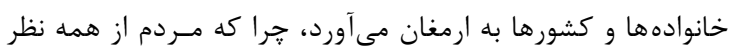

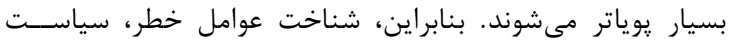

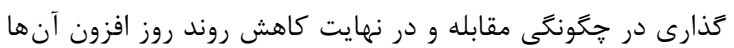

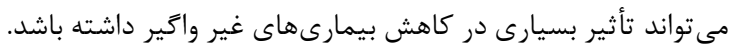

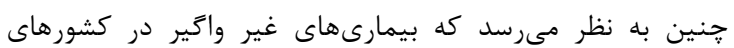

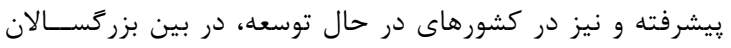

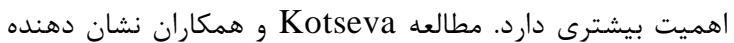

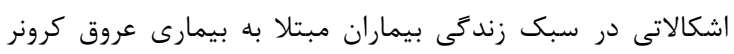

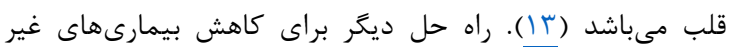

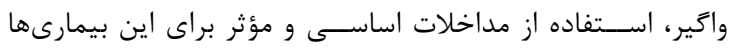

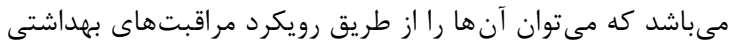

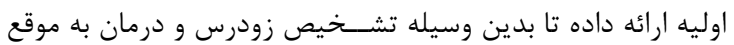
بيمارىها تقويت كردد (أ) ال).
NCD: Non-Communicable ) بيمارىهاى غيرواگير (Diseases

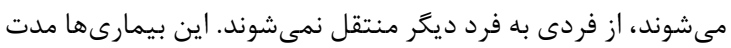

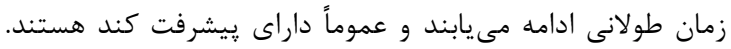

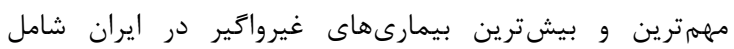

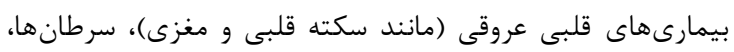

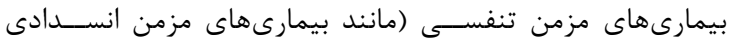

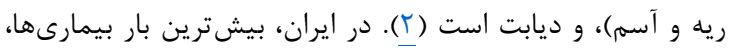

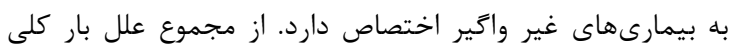

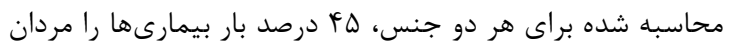

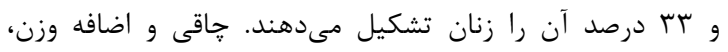

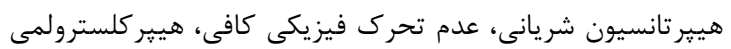

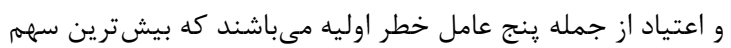

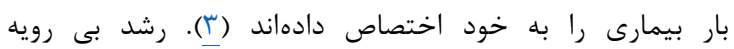

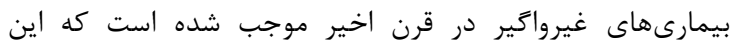

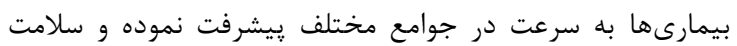

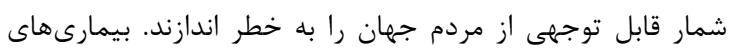

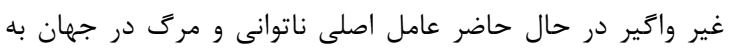

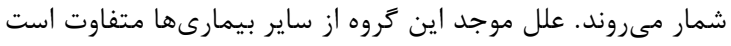

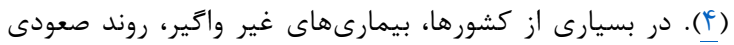

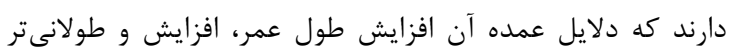

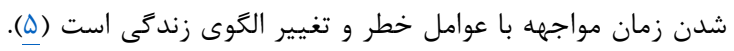

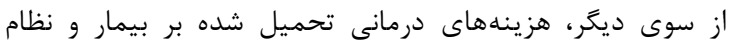

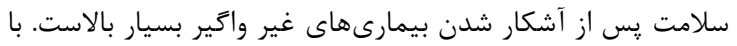

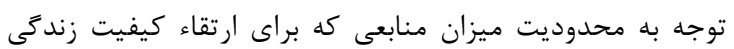

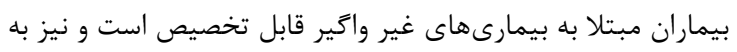

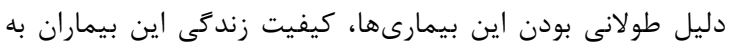

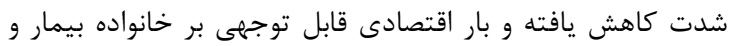

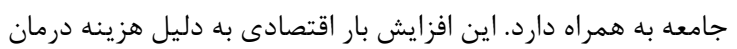

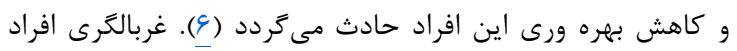

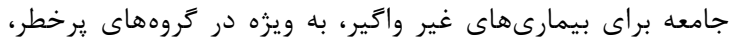

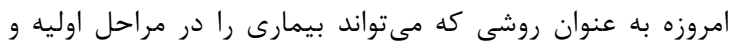

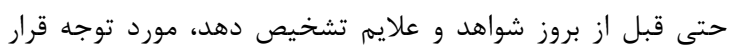

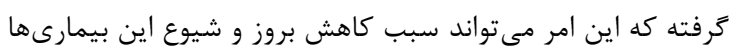

باشد (V) (V) - (V) بيمارىهاى قلبى عروقى به دليل مشكلات ايجاد شده در عروق

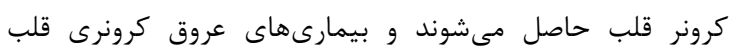

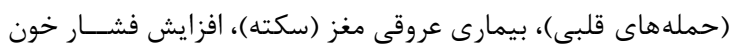

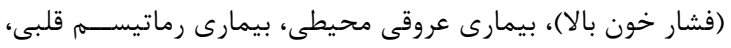

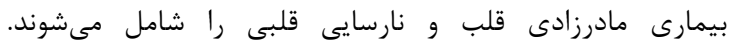

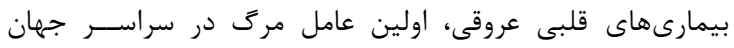

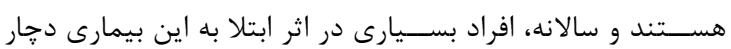

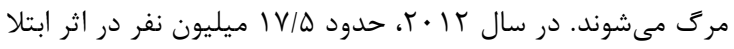

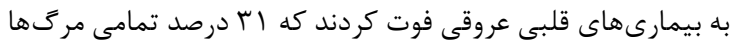

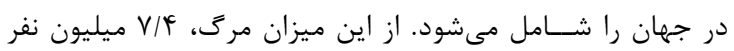

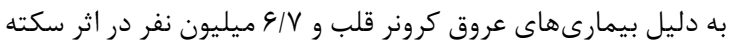

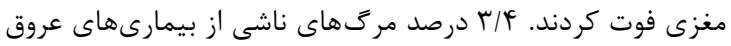


كزارشهاى منتشر شده سازمان بهداشت جهانى، بانك جهانى،

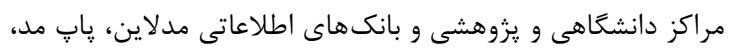

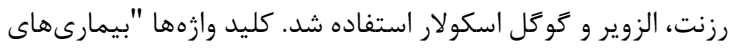

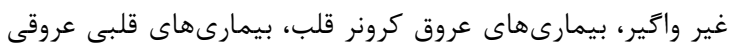

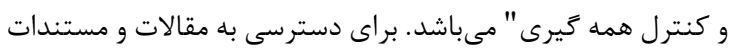

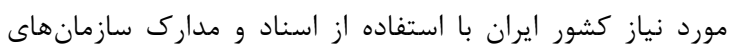

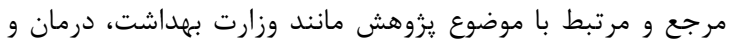

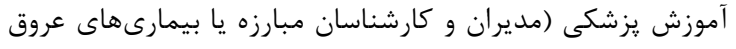

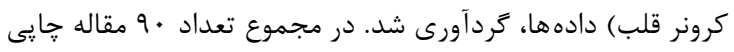

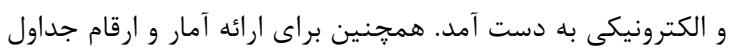

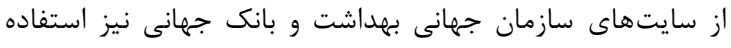

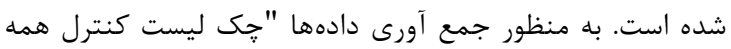

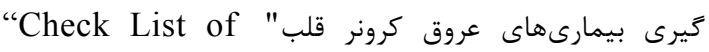
Control on the Epidemic of Coronary Heart با مطالعه كتب و ادبيات، مستندات و مقالات مربوط

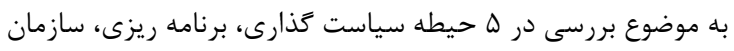

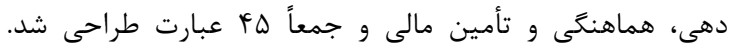
عبارت ها به شكل ليكرت هاهنى قسمتى شامل خيلى زياد (نمره هاه)، زياد

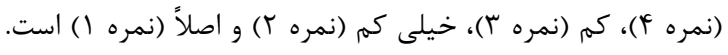

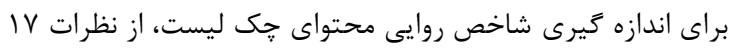

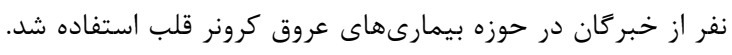

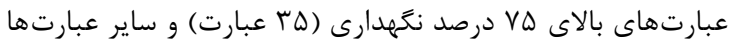

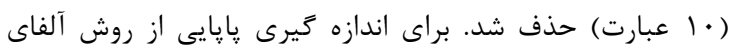

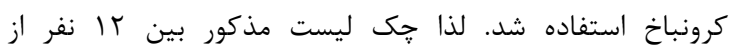

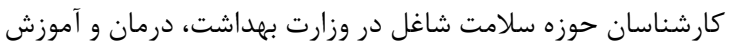

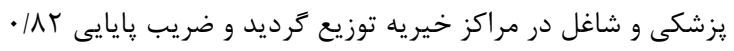

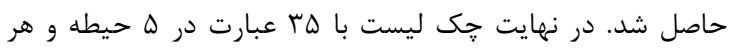

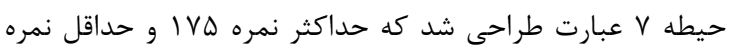

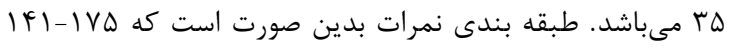

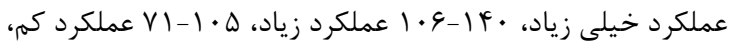

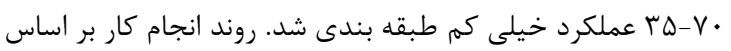

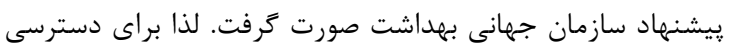

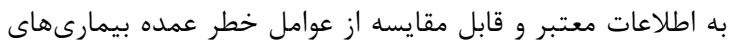

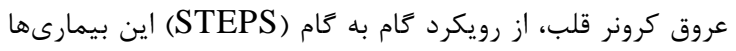

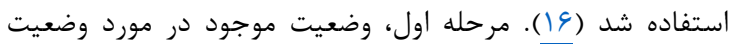

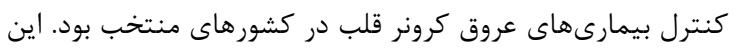

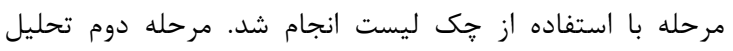

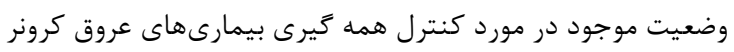

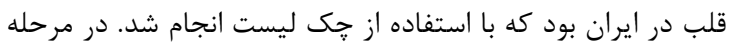

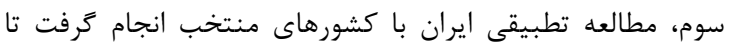

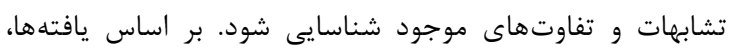

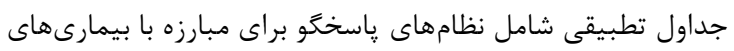

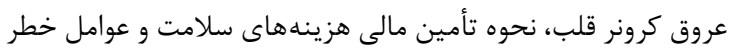

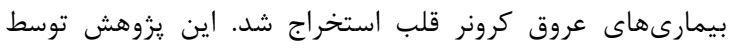

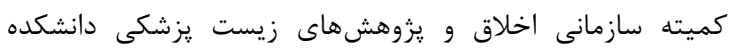

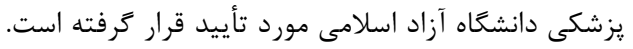

شواهد نشان مىدهد كه جنين مداخلاتى همانند يك سرمايه

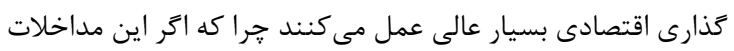

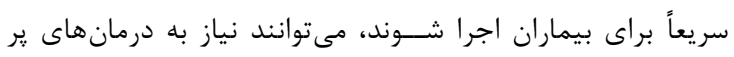

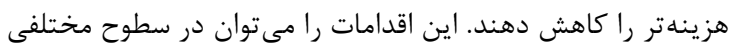

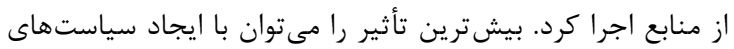

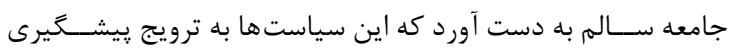

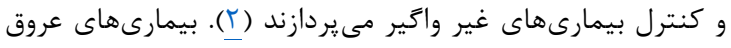

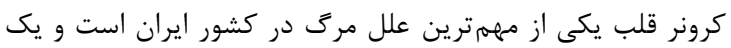

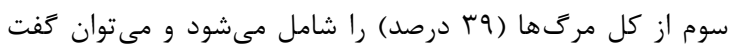

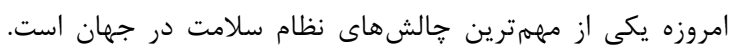

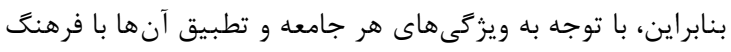

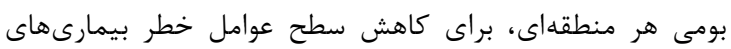

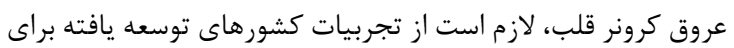

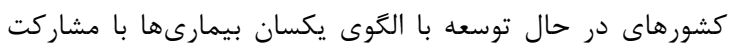

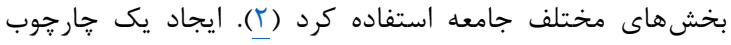
سياست كذارى منسجم شامل تدوين قانون، وضع مقررات و آموزش باري

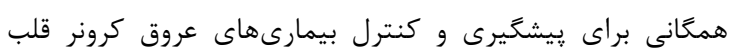

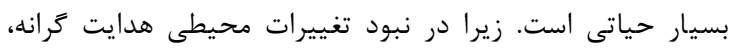

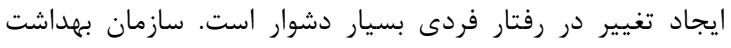

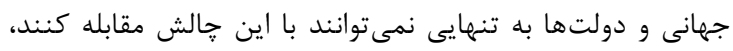

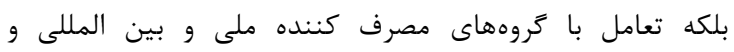
شركتهاى تجارى קند مليتى و سازمان هاى غير دولتى، ضروه

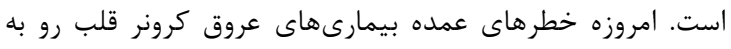

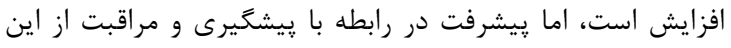

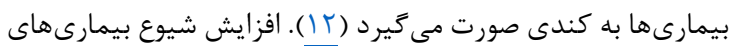

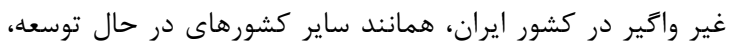

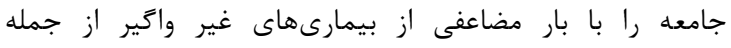

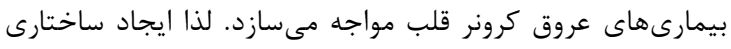

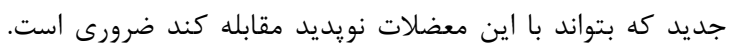
اين يزوهش با هدف مقايسه وضعيت كنترل همه كيرى بيمارى بهاى

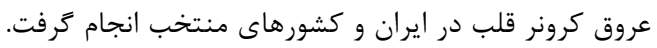

\section{روش كار}

اين يزوهش به صورت تطبيقى در r مرحله انجام شده است. مطالعه

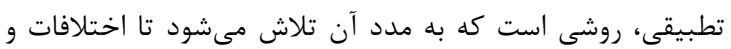

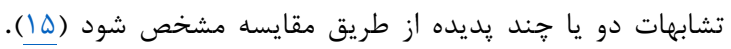

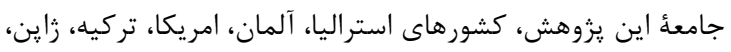

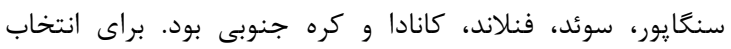

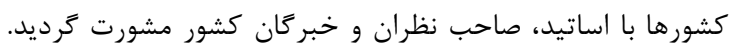
معيارهاى انتخاب كشورها، دارا بودن تجارب مؤثر دان در خصان خصوص

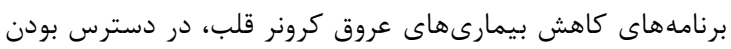

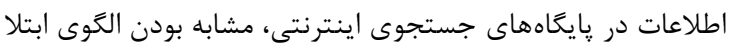

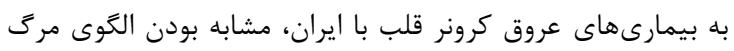

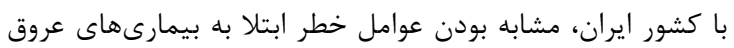

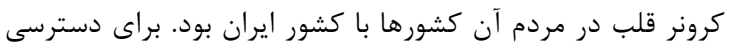

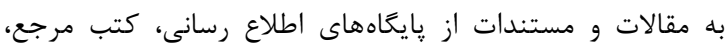

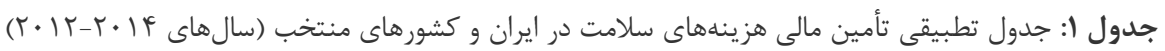




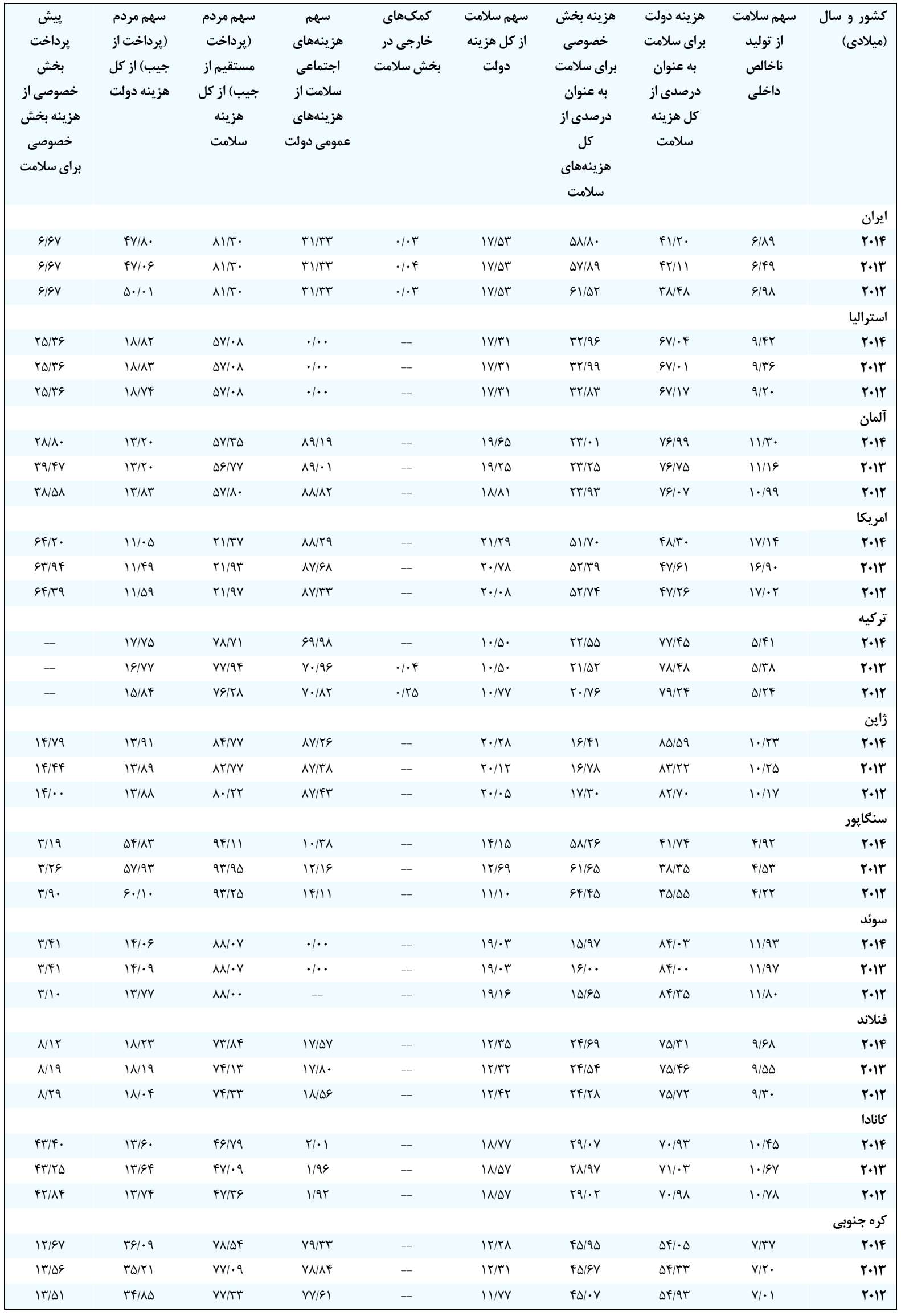




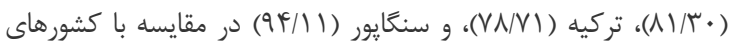

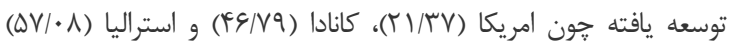

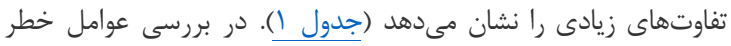

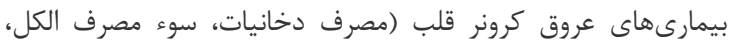

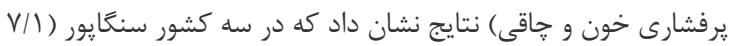

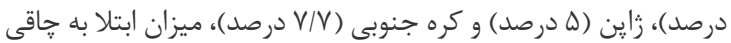

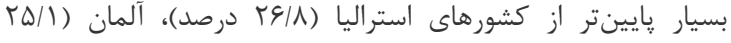

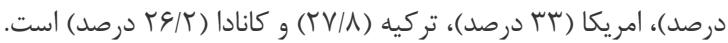

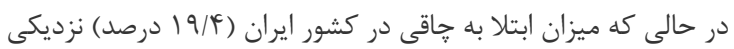

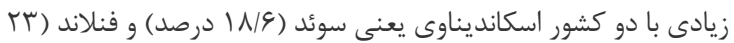

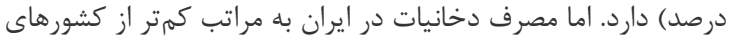

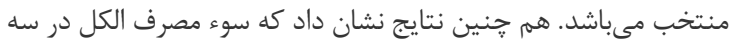

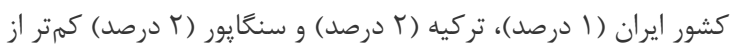

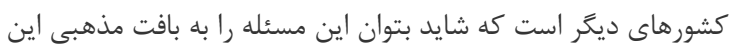

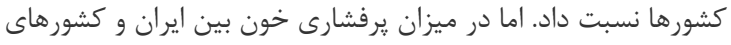

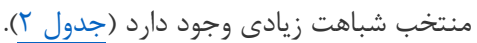

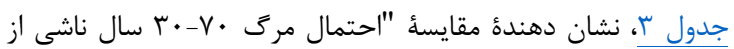

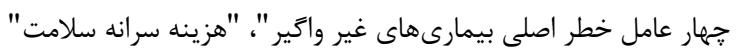

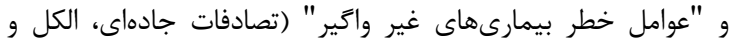

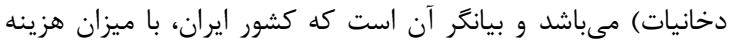

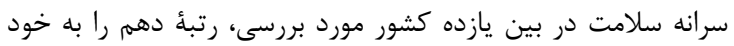

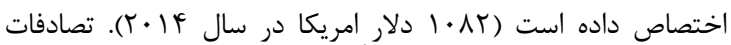

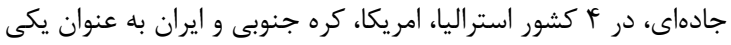

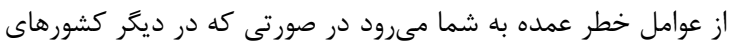

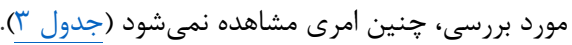

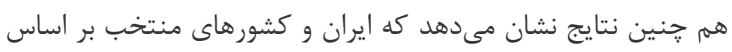

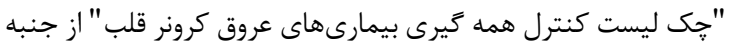

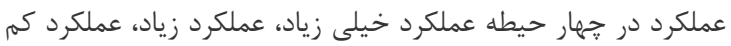

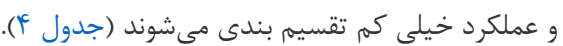

\section{كافتهها}

همأ كشورهاى منتخب از نظر نظامهاى هاى ياسخكَ براى مبارزه با

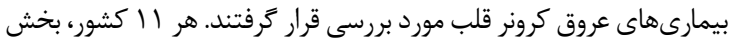

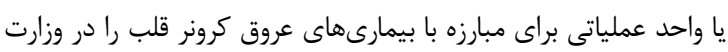

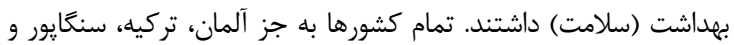

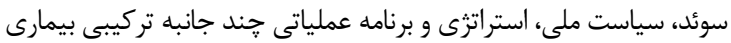
غير واكير و عوامل خطر مشترك بين آنها را در ساختار وزارت بهداشت

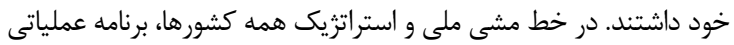

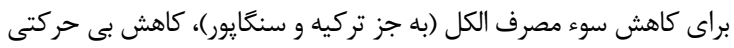

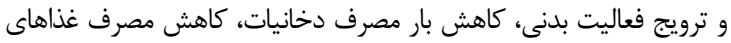

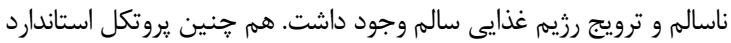

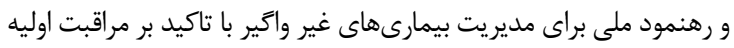

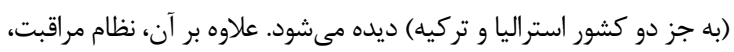

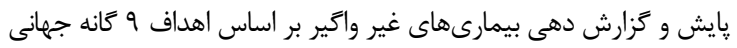
بيمارىهاى غير واكير (به جز كشورهاى استراليا، سوئد، فنلاند و كانادا)

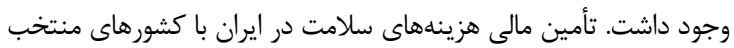
از جهت سهم سلامت از توليد ناخالص داخلى ( Gross Domestic Product

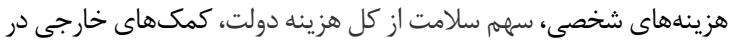

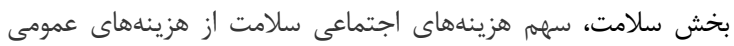

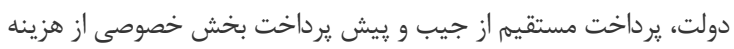

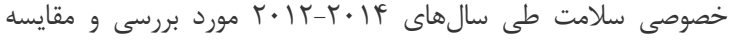

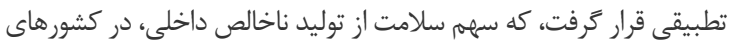

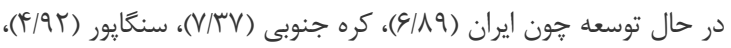

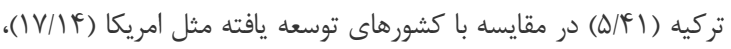

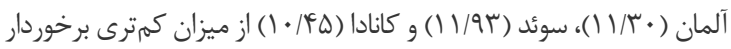

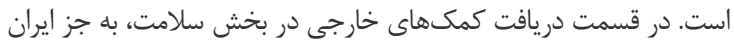

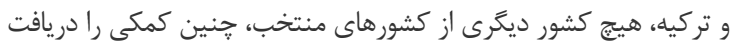

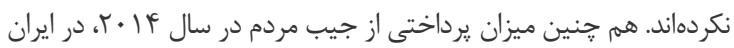

\begin{tabular}{|c|c|c|c|c|c|c|c|c|c|c|c|c|}
\hline \multicolumn{9}{|c|}{ 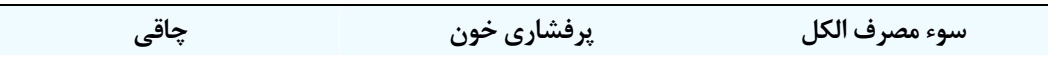 } & \multicolumn{3}{|c|}{ مصرف دخانيات } & \multirow[t]{2}{*}{ كشور } \\
\hline كل & زن & مرد & كل & زن & مرد & كل & زن & مرد & كل & زن & مرد & \\
\hline$\% 19 / 4$ & $\%$ \% & $\%$ IT/F & $\%$ TF/T & \% Tr/F & $\%$ \% & $\% 1 /$ & $\% \cdot / r$ & $\% 1 / V$ & $\% 1 \mathrm{~F}$ & $\% 1<$ & $\%$ & ايران \\
\hline$\%$ TS/A & $\% T V / I$ & $\% T g / F$ & $\% / r \mid / F$ & $\% / \mathrm{V} / \mathrm{Q}$ & $\% / \Delta \Delta / \Delta$ & $\% / T / K$ & $\% / r$ & $\% \mathrm{~V} / \mathrm{r}$ & $\%$. & $\% 19$ & $\% 1$ & استراليا \\
\hline$\%(r \Delta / 1$ & $\%$ TF/F & $\% / T \Delta / q$ & $\%$ & $\%$ TN/F & $\% r F / q$ & $\% 11 / 1$ & $\%$ V/. & $\% 19 \mid \wedge$ & $\%$ & $\% / \Delta$ & $\%$ & آلمان \\
\hline . & $\%$ rr/A & $\%$ \%l/l & $\% \mathrm{~N}$ & $\% \mathrm{IV} / \mathrm{A}$ & $\% N / Y$ & $\% / 9 / r$ & $\% / 9$ & $\% 1 \% / 9$ & - & - & - & امريكا \\
\hline$\%$ TV/A & $\%$ HF & $\% / T / V$ & \%.TT/ & \%TT/A & $\% / r M / r$ & $\% /$. & $\% \cdot 10$ & $\% \mathscr{F} / \mathcal{F}$ & $\%$ TV & $\%$ & $\%$ fT & تركيه \\
\hline$\% . \Delta / \cdot$ & $\% \mathcal{F} / \mathcal{F}$ & $\% / \Delta / \Lambda$ & $\%$ Y T/V & \% & $\% r \cdot 10$ & $\% V / r$ & $\% \mathscr{F}$ & $\% 1 \cdot / 4$ & \% & $\% 11$ & $\%$ rr & زاين \\
\hline$\% \mathrm{~V} / \mathrm{I}$ & $\% \mathrm{~V} / \mathrm{I}$ & $\% /$ & \% Tr/G & $\% \cdot r \cdot 11$ & $\% / r \Delta /$ & $\% /$ & $\% 1 / 4$ & $\% / \mathrm{T} / \mathrm{A}$ & - & - & - & سنغًايور \\
\hline$\% 11 / 9$ & $\% I V / r$ & $\% 19 / 9$ & $\% \mu \cdot 1 \Lambda$ & $\%$ TY/A & $\%$ \% $/ q$ & $\% .9 / r$ & $\% . \Delta / \Delta$ & $\% 1 r / 9$ & $\%$ TF & $\%$ TY & $\% \pi \Delta$ & سوئد \\
\hline$\%$ & \% TY/A & אוrזT & $\% \mathrm{KF} / \mathrm{Q}$ & $\%$ & $\%$ \%N/ & $\%$ & $\% / \Gamma$ & $\% 1 \mathrm{~V} / \mathrm{Q}$ & $\%$ TF & $\%$ & $\%$ \%V & فنلاند \\
\hline$\%$ TS/T & $\%$ TS/F & $\%$ \% & $\% I V / F$ & $\% 19 / 4$ & $\% 1 N / 1$ & $\% 1 \cdot / r$ & $\% . \Delta / \Delta$ & $\% 1 \Delta / 1$ & $\% 11$ & $\% 10$ & $\%$ & كانادا \\
\hline$\% \mathrm{~V} / \mathrm{V}$ & $\%$ \%/N & $\% / T$ & $\% \mid 9 /$ & $\% \mathrm{~F} / \mathrm{r}$ & $\%$ IVIA & $\%$ & $\% / \% / 9$ & $\%$.rI & $\%$ \% & $\%$ & $\% q q$ & كره \\
\hline
\end{tabular}




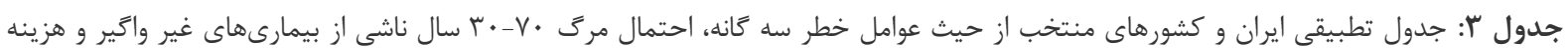

\begin{tabular}{|c|c|c|c|c|c|}
\hline \multicolumn{3}{|c|}{ عوامل خطر بيمارىهاى غيرواكير } & هزينه سرانه سلامت (د) (دلار امريكا) & 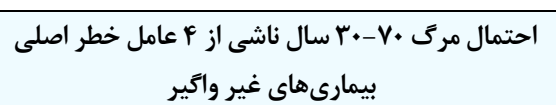 & كشور \\
\hline دخانيات & 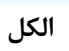 & تصادفات جادهاى & & & \\
\hline$\checkmark$ & $\checkmark$ & $\checkmark$ & $1 \cdot 1 r$ & $\% \mathrm{lV}$ & ايران \\
\hline$\checkmark$ & $\checkmark$ & $\checkmark$ & frov & $\%$ & 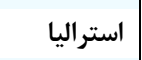 \\
\hline$\checkmark$ & $\checkmark$ & - & DINT & $\%$ & آلمان \\
\hline$\checkmark$ & $\checkmark$ & $\checkmark$ & $q 4 \cdot r$ & $\% 14$ & |مريكا \\
\hline$\checkmark$ & $\checkmark$ & - & 1.48 & $\% 11$ & | تركيه \\
\hline$\checkmark$ & $\checkmark$ & - & TVYV & $\%$ & | - ماين \\
\hline$\checkmark$ & $\checkmark$ & - & $F \cdot F V$ & $\%$. & 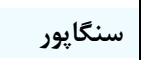 \\
\hline$\checkmark$ & $\checkmark$ & - & $\Delta T 19$ & $\%$. & | سوئد \\
\hline$\checkmark$ & $\checkmark$ & - & $r v \cdot 1$ & $\% 11$ & | فنلاند \\
\hline$\checkmark$ & $\checkmark$ & - & $|q| q \mid$ & $\% 11$ & كانادا \\
\hline$\checkmark$ & $\checkmark$ & $\checkmark$ & TQTI & $\% 9$ & كره جنوبى \\
\hline
\end{tabular}

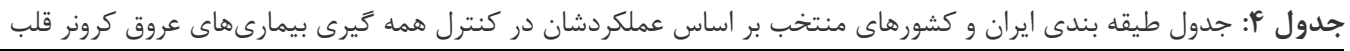

\begin{tabular}{|c|c|c|c|}
\hline 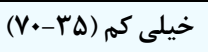 & كم (1) & 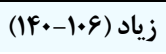 & خيلى زياد (IVD-IFI) \\
\hline ايران & رازين & امريكا & آلمان \\
\hline تركيه & سنغايور & استراليا & سوئد \\
\hline & كره جنوبى & فنلاند & كانادا \\
\hline
\end{tabular}

بيمه درمانى ملى بنا نهاده شد. برنامه يِيشخيرى جامعه محور داراى

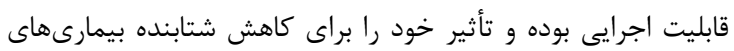

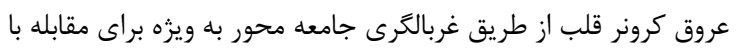

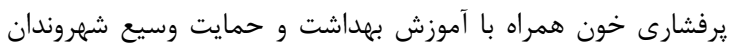

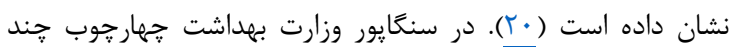

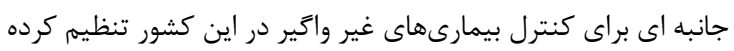

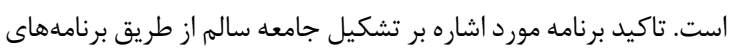

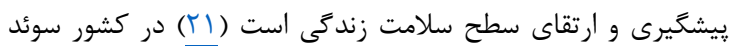

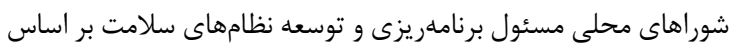

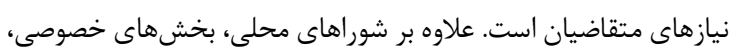

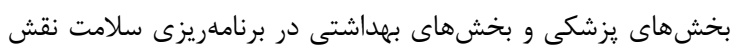

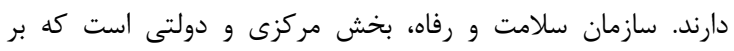

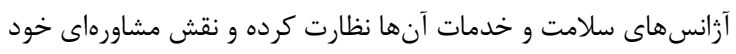

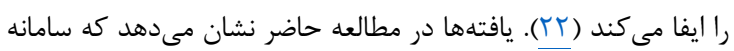
طبقه بندى بيمارىهاى عروق كرونر قلب در كشورهاى توسعه يافته

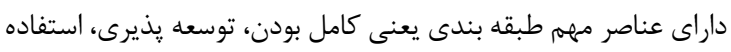

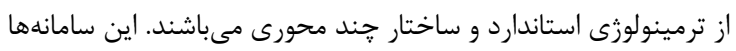
مزايا و محدوديتهايى دارند. محدوديت مشترك در سامانه طبقه بندى

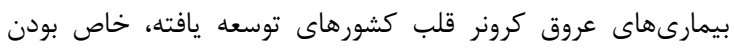

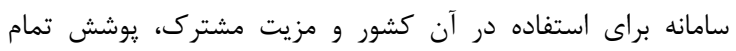

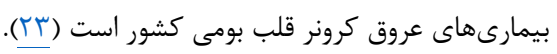

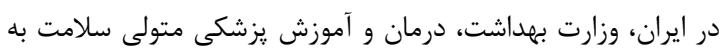

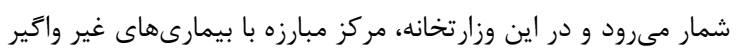

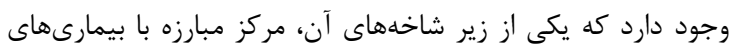

اين يزوهش با هدف مقايسه وضعيت كنترل همه كيرى بيمارىهاى

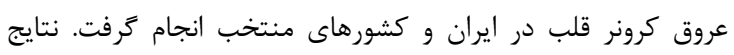

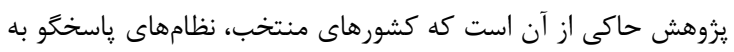

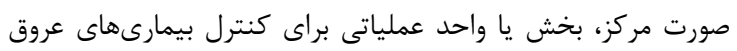

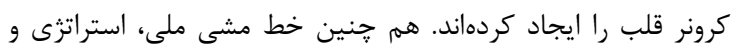

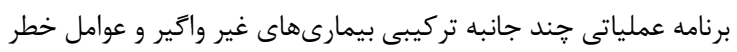

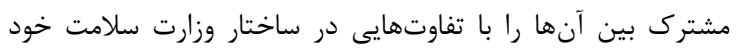

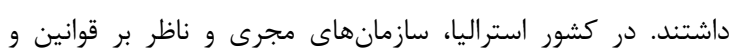
مقررات حاكم بر سامانهاي عروق كرونر قلب وجود دارند و از ساخت ساختار سامانه طبقه بندى بيمارىهاى عروق كرونر قلب قوانين سازمان سان جهانى كرون

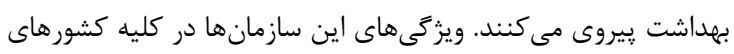

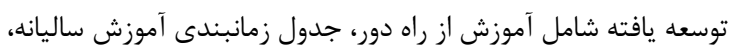

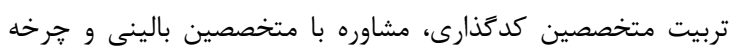

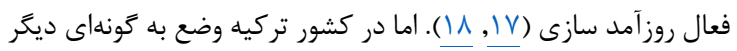

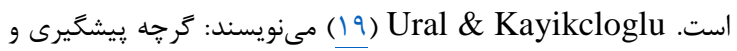
درمان بيمارىهاى غيرواكير، هدف اصلى وزارت سلامت است، هيج

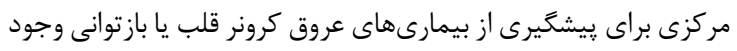

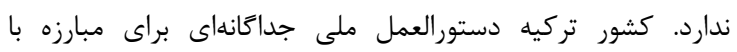

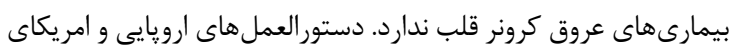

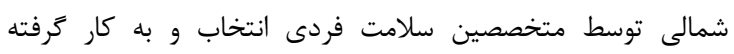

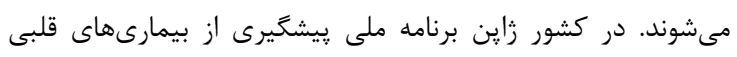

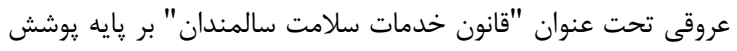


حاصل از فروش منابع نفتى بوده است و ميزان مشاركت از طريق ماليات

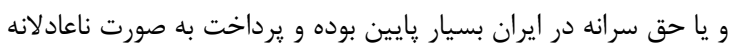

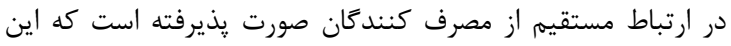

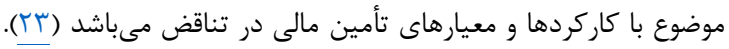

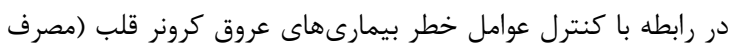

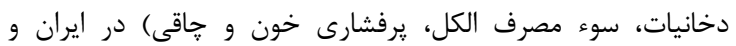

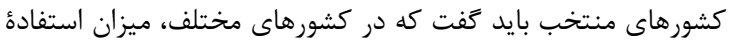

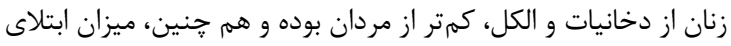

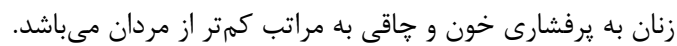

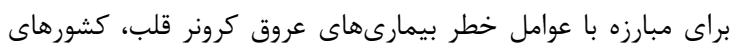

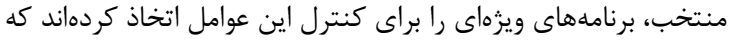

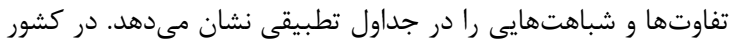

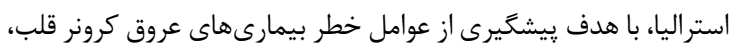

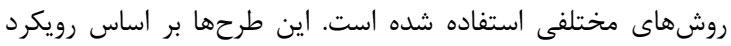

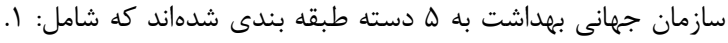

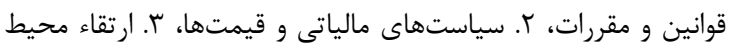

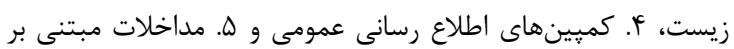

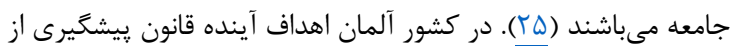

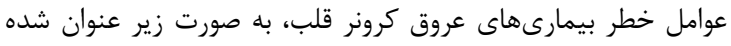

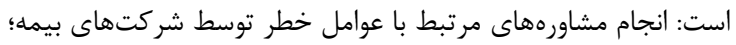

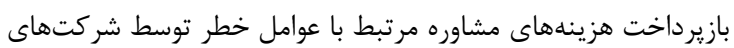

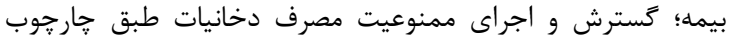

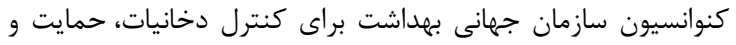

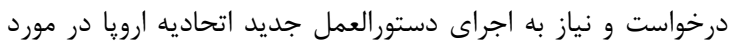

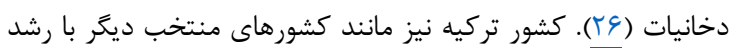

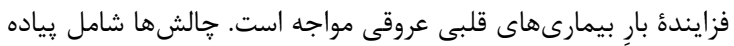

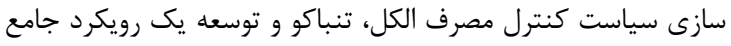

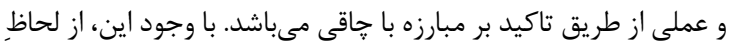

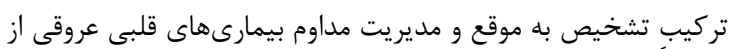

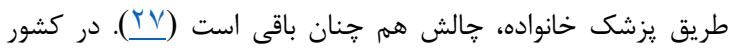

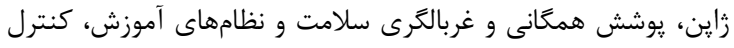

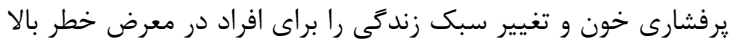

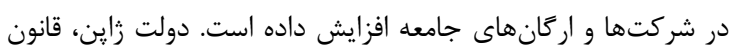

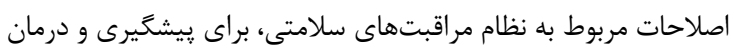

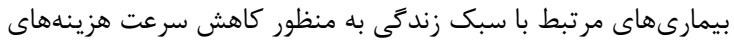

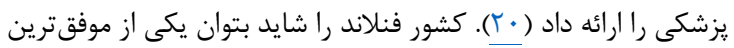

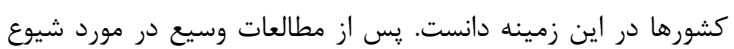

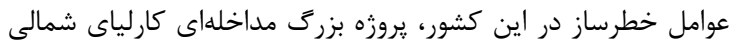

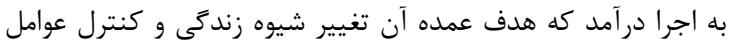

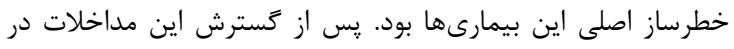

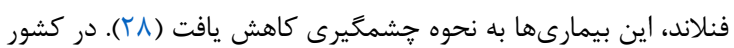

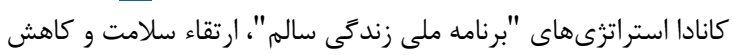

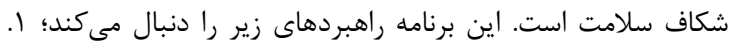

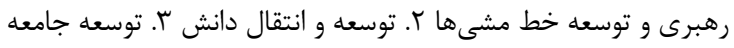

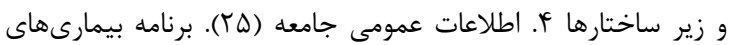

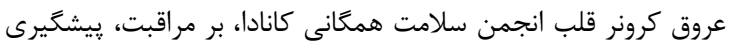

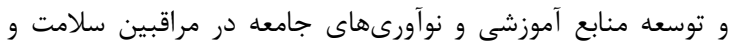

قلبى عروقى مىباشد. كميته ملى ييشخيرى و كنترل بيمارىهاى غير

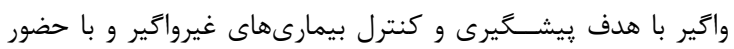

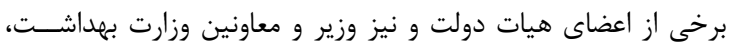

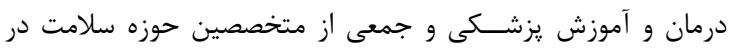

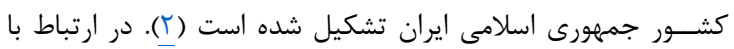

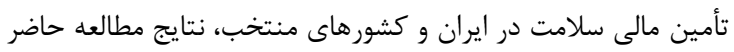

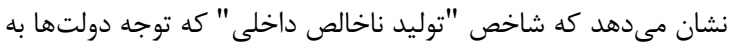

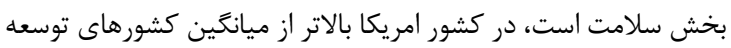

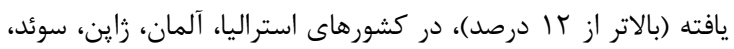

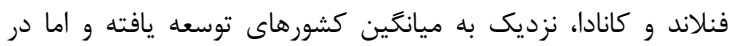

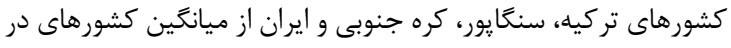

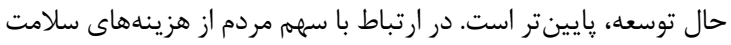

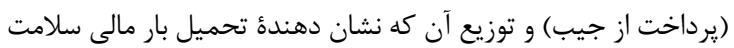

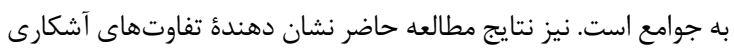

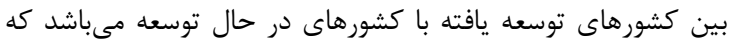

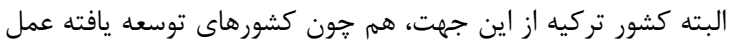

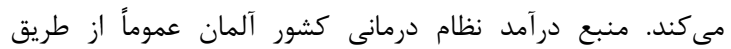

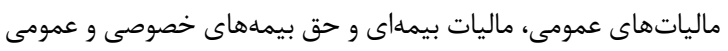

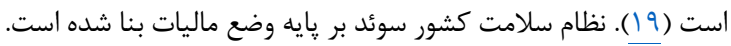

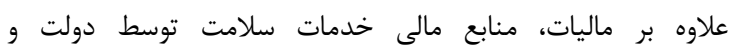

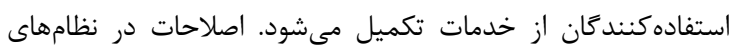

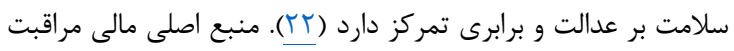

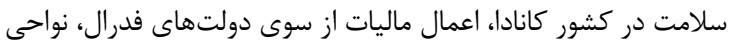

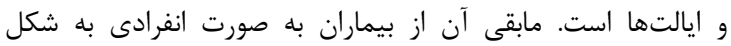

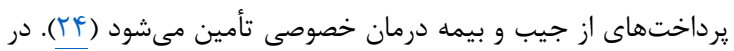

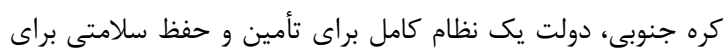

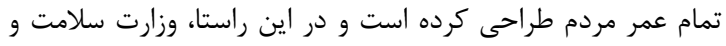

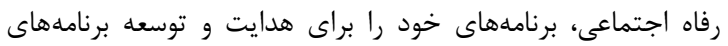

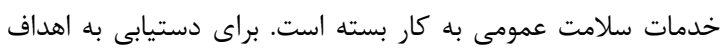

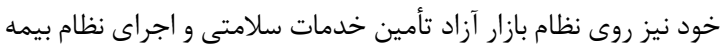

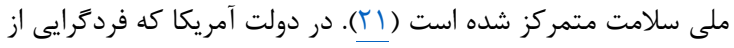

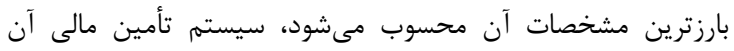

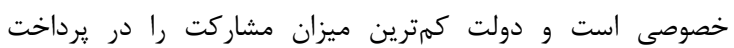

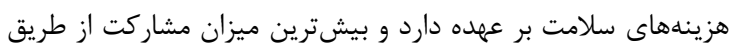
بيمههاى خصوصى امكان يذير است. البته مشاهده مى شيود كه به حضور

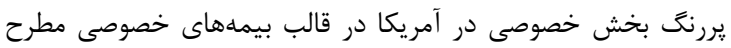

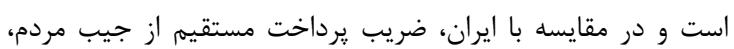
پايينتر است (TY) ايران در مقايسه با كشورهايى همانند آلمان و تر كيه يك سيستم تأمين

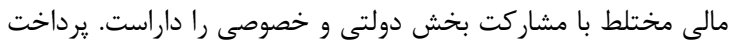

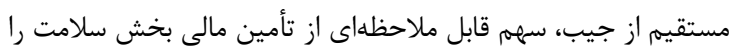

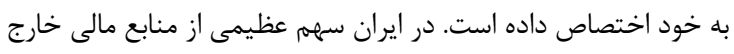

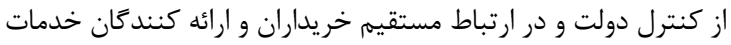

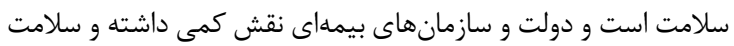

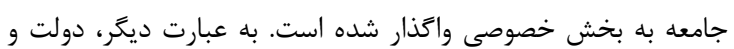

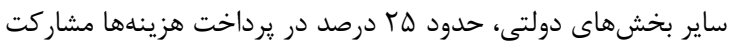

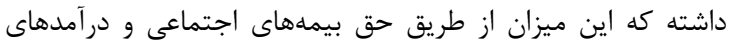




$$
\begin{aligned}
& \text { بيمارىهاى عروق كرونر قلب مبتلا نشده و كيفيت زندگى بهترى و در } \\
& \text { نهايت اميد به زندگى بيشترى عرون داشته باشند. } \\
& \text { نتيجه تيرى }
\end{aligned}
$$

مقايسه نظامهاى هاى پاسخكو و تأمين مالى سلامت و عوامل خطر

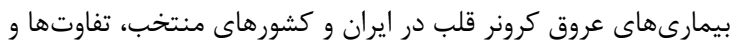

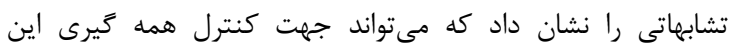

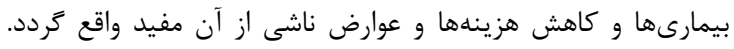

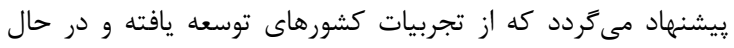

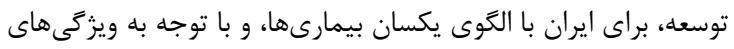

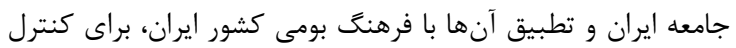

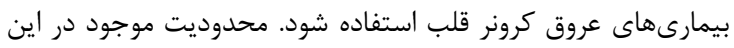

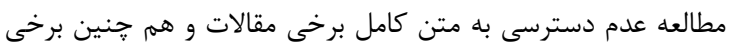
بانكهاى اطلاعاتى بود.

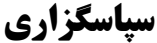

اين مقاله مستخرج از رساله دكترى ويدا صادق زاده دانشجوى دانشكاه

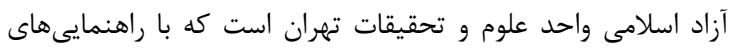

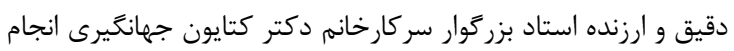

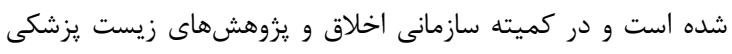

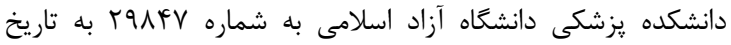

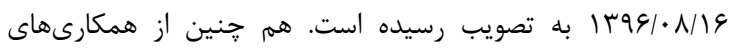
مشفقانه و نظرات ارزشمند مديران و كارشناسان محترم وزارت بهداشت،

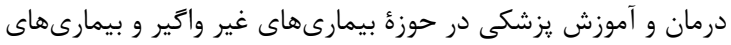

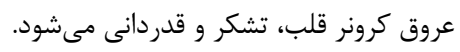

\section{References}

1. Health Do. Public participation development program and inter-institutional coordination in the form of "Specialist volunteers". Iran: The Ministry of Health and Medical Education, 2013.

2. Control INCfNPa. National Action Plan for Prevention and Control of Non-Communicable Diseases and the Related Risk Factors in the Islamic Republic Of Iran, 2015-2025. Tehran, Iran: Iranian National Committee for NCDs Prevention and Control, 2015.

3. Karimi S, Javadi M, Jafarzadeh F. [Economic burden and costs of chronic diseases in Iran and the world]. Health Inf Manage. 2012;8(7):984-96.

4. Organization WH. Summary Surveillance of risk factors for non-communicable diseases. The WHO STEPwise approach Non-communicable diseases and mental health. Geneva: WHO/NMH/CCS, 2003.

5. Eshrati B, Hasanzadeh J, Mohammad Beigi A. [Calculation of population attributable burden of excess weight and obesity to non-contagious diseases in Markazi province of Tehran]. Semnan Medic Sci J. 2009;11(2):83-90.

6. Jahangiri K, Tabibi S, Maleki M, Alamdari S. [A Comparative Study of Community-Based Disaster

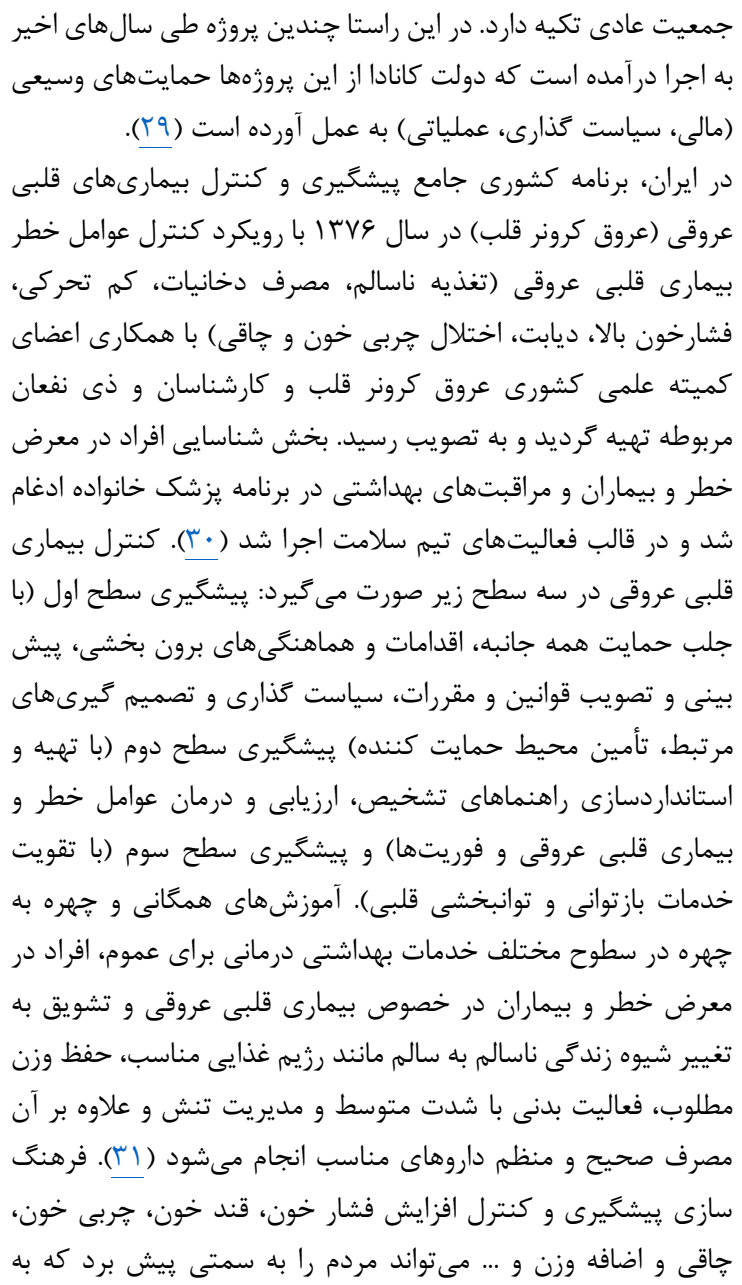

Management in Selected Countries and Providing a Model for Iran]. Payesh Health Monit. 2008;8(1):4957.

7. Gordis L. [Epidemiology]. 9th ed. Rasht, Iran: Gap publication; 2008.

8. Lofvenmark C, Saboonchi F, Edner M, Billing E, Mattiasson AC. Evaluation of an educational programme for family members of patients living with heart failure: a randomised controlled trial. J Clin Nurs. 2013;22(1-2):115-26. DOI: 10.1111/j.13652702.2012.04201.x PMID: 22946864

9. Hinkle J, Cheever K. Textbook of Medical-Surgical Nursing. 13th ed. Tehran: Heidary publication; 2014.

10. Kasper D, Fauci A, Hauser S, Lango D, Jameson J, Loscalzo J. [Harrison's Principles of Internal Medicine Cardiovascular Disorders]. Tehran, Iran: Arjomand Book publication; 2015

11. Yavari P. The epidemiological reference of common diseases in Iran (non-communicable diseases). 2nd ed. Tehran, Iran: Shahid Beheshti University of Medical Sciences; 2014.

12. Javadi H. [Non-communicable diseases, predominant epidemics]. Res Med. 2005;19(1):9-12. 
13. Kotseva K, Wood D, De Backer G, De Bacquer D, Pyorala K, Keil U, et al. EUROASPIRE III: a survey on the lifestyle, risk factors and use of cardioprotective drug therapies in coronary patients from 22 European countries. Eur J Cardiovasc Prev Rehabil. 2009;16(2):121-37. DOI: 10.1097/HJR. Ob013e3283294b1d PMID: 19287307

14. Green G, Kennedy P, McGown A. Management of Multi-Method Engineering Design Research. Glasgow, UK: Department of Mechanical Engineering University of Glasgow; 2002.

15. Erabi S. [Comparative Research]. 2nd ed. Tehran, Iran: Office of Cultural Research; 2004.

16. Kouhpayehzadeh Esfahani J, Asgari F, Azimi S, Rafei A, Bejani S. [Surveillance of risk factors for noncommunicable diseases]. Tehran, Iran: Department of Health, Center of noncommunicable diseases control, 2012.

17. PROVE/ACS. Persian Registry Of cardio Vascular disease Iran: PROVE/ACS; 2015. Available from: http://prove.mui.ac.ir/index.php?type $=1 \& \mathrm{~s}=888$.

18. Safdari R, Malaki M, Ghorbani V, Monajjemi F. [Comparison of Coronary artery diseases classification system in selected countries with Iran]. J Qazvin Univ Med Sc. 2009;13(2):44-50.

19. Ural D, Kayikcloglu M. National CVD prevention coordinator for Turkey (Prepared for the EACPR "Country of the Month" initiative). Turkey: WHO, 2014.

20. Iso H. A Japanese health success story: trends in cardiovascular diseases, their risk factors, and the contribution of public health and personalized approaches. EPMA Journal. 2011;2(1):49-57. DOI: 10.1007/s13167-011-0067-0

21. Health HKDo. [Global Perspective on Noncommunicable Disease Prevention and Control] Hong Kong: Hong Kong Department of Health; 2010 [cited 2016]. Available from: http://www.dh.gov.hk/ english/pub_rec/pub_rec_ar/pdf/.../chap_3.pdf/
22. WHO. 2014 Stockholm, Sweden: World Health Organization; Sweden [cited 2017]. Available from: http://www.who.int/countries/swe_en.pdf

23. Association IUES. The financial health system in the countries of the world. . Iran Iran Urban Economics Scientific Association, 2015.

24. Marchildon G. Canada: Health system review. Health Syst Transit. 2013;15(1):1-179. PMID: 23628429

25. Health AGDo. population-level prevention initiatives and interventions, prevention of coronary artery disease, diabetes and chronic kidney disease. Australia: Australian Government Department of Health, 2011.

26. Gohlke H, Keil U. National CVD prevention coordinators for Germany. Country of the monthGermany Germany: European society of Cardiology; 2017 [cited 2017]. Available from: https://www. escardio.org/Sub-specialty-communities/EuropeanAssociation-of-Preventive-Cardiology-(EAPC).

27. Jakab M, Smith B, Sautenkova N, Abdraimova A, Temirov A, Kadyralieva R. Better non-communicable diseases outcomes: Challenges and opportunities for health systems. Country assessment, Kyrgyzstan. Kyrgyzstan: World Health Organization, Regional office for Europe, 2015.

28. Puska P. Successful prevention of non-communicable diseases: 25 year experiences with North Karelia Project in Finland. Public Health Med. 2002;4(1):5-7.

29. Canada HaSFo. Healthy Living and Chronic Disease (HLCD) - List of funded projects for 2010-2013. Canada: Public Health Agency 2013.

30. Samavat T, Hojjatzadeh E. Prevention and control of Coronary artery diseases programs. Tehran, Iran: Cardiovascular Administration, Center of management of noncommunicable diseases, Health Ministry of Iran, 2011.

31. Control INCfNPa. National action plan for prevention and control of non-communicable disease and the related risk factors in the Islamic Republic of Iran, 2015-2025. Iran: National Committee for NCDs Prevention and Control; 2015. 